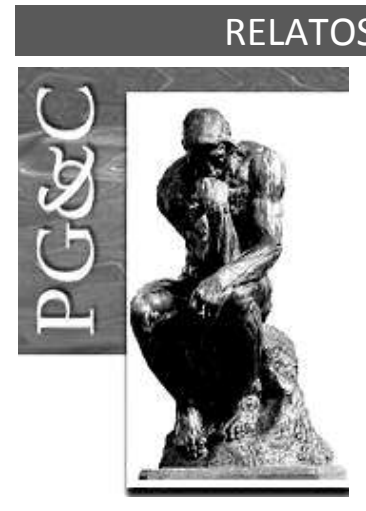

\title{
INSERÇÃO PROFISSIONAL: UMA ANÁLISE BIBLIOMÉTRICA DOS ESTUDOS BRASILEIROS EM BASES DE DADOS CIENTÍFICAS
}

\author{
Jhony Pereira Moraes \\ Doutorando em Administração pela Universidade Federal do Rio Grande \\ do Sul, Brasil. Professor do Centro Universitário FADERGS, Brasil. \\ E-mail: jhonymoraes@hotmail.com.br \\ Sidinei Rocha de Oliveira \\ Doutor em Administração pela Universidade Federal do Rio Grande do Sul, \\ Brasil. Professor da Universidade Federal do Rio Grande do Sul, Brasil. \\ E-mail: sroliveira@ea.ufrgs.br
}

\begin{abstract}
Resumo
O artigo objetiva apresentar uma análise bibliométrica sobre o tema inserção profissional nos estudos brasileiros, em cinco bases de dados e sem delimitação de série-histórica. Uma busca preliminar em tais bases dados aponta 571 artigos que possuem relação com o tema, porém, somente 51 estudos são considerados válidos: quatro artigos da base SPELL, 22 artigos da SciELO, três artigos da PePSIC e 22 artigos do portal de periódicos CAPES. Nenhum artigo da base de dados EBSCO atende ao tema e aos critérios estabelecidos na pesquisa. Os trabalhos analisados, independente do ano de publicação ou do cenário socioeconômico que os circundam, problematizam a crise do mercado de trabalho e da educação, a juventude sob o olhar das desigualdades sociais e econômicas, as iniciativas privadas e públicas, especificamente políticas públicas educacionais e profissionais com atendimento prioritário à camada juvenil de baixa renda; e as identidades, expectativas e experiências profissionais. Contudo, sente-se falta de um avanço no campo, isto é, estudos que renovem as perspectivas de entendimento ou que concentrem ainda mais seus esforços nas realidades investigadas. Percebe-se a possibilidade de associação da teoria de inserção francesa com outros quadros teóricos, pois permite analisar múltiplos grupos sociais.
\end{abstract}

Palavras-chave: Inserção Profissional. Mercado de trabalho. Revisão bibliométrica.

\section{PROFESSIONAL INSERTION: \\ A BIBLIOMETRIC ANALYSIS OF BRAZILIAN STUDIES IN SCIENTIFIC DATABASES}

\begin{abstract}
The article aims to present a bibliometric analysis on the theme professional insertion in Brazilian studies, in five databases and without historical series delimitation. A preliminary search in these databases shows 571 articles that are related to the theme, but only 51 studies are considered valid: four articles from SPELL database, 22 articles from SCIELO, three articles from PePSIC and 22 articles from the CAPES journal portal. No article in the EBSCO database meets the theme and criteria set out in the survey. The analyzed works, regardless of the year of publication or the socioeconomic scenario that surround them, problematize the crisis of the labor market and education, youth under the perspective of social and economic inequalities, private and public initiatives, specifically educational and public policies. professionals with priority assistance to the low income youth group; and the identities, expectations and professional experiences. However, there is a lack of progress in the field, that is, studies that renew perspectives of understanding or focus even more on the investigated realities. It is possible to associate the French insertion theory with other theoretical frameworks, since it allows to analyze multiple social groups.
\end{abstract}

Keywords: Professional Insertion. Labour market. Bibliometric review.

Perspectivas em Gestão \& Conhecimento, João Pessoa, v. 9, n. 3, p. 81-101, set./dez. 2019. DOI: http://dx.doi.org/10.21714/2236-417X2019v9n3p81

http://periodicos.ufpb.br/ojs2/index.php/pgc. ISSN: 2236-417X. Publicação sob Licença (cc) EY-NC-ND 


\section{INTRODUÇÃO}

As transformações socioeconômicas desde a década de 1990 vem apresentando um considerável impacto sobre as relações de trabalho, emergindo diferentes contratos, crescimento de vínculos precarizados e negociações trabalhistas cada vez mais informais. Percebe-se que tais mudanças na conjuntura social também interferem na própria organização do mercado de trabalho, com impactos sobre a reformulação das leis trabalhistas e uma possível mudança na relação entre Estado, organizações, sindicatos e demais agentes interessados (GUIMARÃES, 2013; SANTOS, 2013; VOLKMER MARTINS; ROCHA-DE-OLIVEIRA, 2017).

Assim, a alteração da esfera do trabalho instiga uma competição entre jovens e adultos pelos escassos empregos. Tal situação acompanha o ritmo de desenvolvimento do mercado e a lógica da teoria do capital humano, onde o indivíduo é responsável pela sua qualificação e pelas consequências de suas escolhas no campo do trabalho, como também cabe a ele a garantia de sua empregabilidade e competitividade (CATTANI, 2011; VOLKMER MARTINS; ROCHA-DE-OLIVEIRA, 2017).

Além disso e simultânea a isso está a expansão da Educação Superior (INEP, 2017; VOLKMER MARTINS; ROCHA-DE-OLIVEIRA, 2016, 2017), a qual se apresentou como uma saída para o sucesso profissional do jovem brasileiro. Entretanto, apesar de sua popularização através de políticas públicas nos últimos 10 anos, tais como o PROUNI e o SISU e os programas de concessão de crédito (FIES e formas de financiamento estudantil internos às instituições), observa-se que o seu produto (o diploma universitário) não mais garante o acesso imediato ao mercado de trabalho (OLIVEIRA; WETZEL, 2009).

Em decorrência da seletividade de escolha de profissionais para os cargos nas empresas, que assola até mesmo os mais qualificados, muitos dos jovens que se formam passam a ocupar posições laborais inferiores à qualificação que possuem, o que denominamos de rebaixamento social ou déclassement (PEUGNY, 2014; VOLKMER MARTINS, 2016). Com isso, nota-se haver uma falta de mão-de-obra qualificada no mercado, caso em que se propõe analisar a inserção profissional juvenil (VOLKMER MARTINS; ROCHA-DE-OLIVEIRA, 2016, 2017).

O desenvolvimento de estudos sobre esse tema é decorrente de três motivos, de acordo com Rocha-de-Oliveira e Piccinini (2012a): 1. O seu surgimento na França como fator e interesse político devido ao quadro de emprego constituído pela juventude do país, que apresentam alta qualificação e dificuldades de colocação no mercado. 2. A emergência de estudos teóricos que sustentassem as diferentes abordagens sobre o tema. 3. E a necessidade de novos estudos que explorem novos olhares sobre a inserção, perpassando níveis educacionais e grupos sociais diversificados.

Portanto, este estudo busca retratar a inserção profissional e apresentar uma análise bibliométrica da produção científica nessa área até o ano de 2017. Para tanto, foram realizadas pesquisas em bases de dados científicas, sendo SPELL, SciELO, EBSCO, PEPSIC e CAPES, sem determinação de série-histórica.

O estudo apresenta, além dessa breve introdução, um referencial teórico sobre inserção profissional (discutindo sua origem e o conceito), a metodologia (reforçando o caráter bibliométrico do estudo, a forma de coleta dos dados, os pontos de análise dos artigos selecionados), a apresentação e discussão dos resultados (salientado os principais elementos discutidos nos artigos em análise) e, por fim, as considerações finais.

\section{QUADRO TEÓRICO}

\subsection{Inserção profissional: origem e conceito}

Perspectivas em Gestão \& Conhecimento, João Pessoa, v. 9, n. 3, p. 81-101, set./dez. 2019. 
A expressão "inserção profissional" é característica dos estudos franceses, sendo que os seus primeiros registros datam de 1970 em textos legislativos da época. A transição do jovem para o mercado de trabalho teve diferentes denominações: entrada na vida ativa, entrada na vida adulta, transição escola para o trabalho, entre outros. Contudo, foi aquela expressão que se consolidou para indicar essa importante fase de vida do indivíduo (DUBAR, 2001; ALVES, 2007; ROCHA-DE-OLIVEIRA; PICCININI, 2012a).

A França do século XX reflete os problemas vigentes da inserção de jovens no mercado de trabalho: um contingente juvenil com alta escolarização e grandes dificuldades de integração ao trabalho, percorrendo também casos de desemprego e exclusão social. Diante dessa problemática, fala-se que a situação laboral dos jovens franceses se estabiliza como um problema social que permeia diferentes sociedades e, com isso, afirma-se que a inserção profissional é considerada um aspecto sócio-histórico, pois acompanhou o desenvolvimento de tal sociedade (VINCES, 1981; DUBAR, 2001; ALVES, 2007; ROCHA-DE-OLIVEIRA; PICCININI, 2012a).

Contudo, foi em 1980 que o Governo francês concentrou esforços sobre a inserção profissional de sua população jovem, considerando-a como uma demanda social. Para tanto, passa a acompanhar tal situação, tratando, principalmente, os casos de desemprego, exclusão juvenil; e a relação entre o mercado de trabalho e o sistema de ensino. No Brasil, os estudos acerca da inserção profissional iniciam por volta de 1970, voltados para os jovens de classe média. Mas, com a expansão do ensino superior, outras realidades sociais passaram a integrar essa análise (DUBAR, 2001; ALVES, 2007; TARTUCE, 2007; ROCHA-DE-OLIVEIRA, 2009, 2012).

Entretanto, a crise do emprego em 1990 influenciou a queda dos postos de trabalho, em especial para aqueles responsáveis pelo sustento da família. Na mesma época, estudos sobre a inserção dos jovens brasileiros sobre educação e qualificação emergem, bem como análises mais complexas sobre a relação com o trabalho (representação, desemprego, processo de transição escola-trabalho) (ALVES; PAULO, 2013; AMARAL; WALTHER, 2013; CASTRO; ANDRADE, 2013; CORROCHANO, 2013; MARCOLINO; HORIE; PELATIERI, 2013; MENEZES; UCHOA, 2013; MORETTO; REMY, 2013; SOUTO et al., 2013).

A inserção surge quando se tem o triângulo família-escola-trabalho formalizado e suas partes bem definidas. Inclui-se nessa fase a representatividade do ensino secundário e das universidades, aos quais foram atribuídos o sucesso profissional oriundo da posse de um diploma - que determina a colocação profissional e social - e a organização da sociedade pelo sistema educacional através da massificação do ensino (CHARLOT; GLASMAN, 1998, apud ALVES, 2007).

Sobretudo, a inserção profissional é entendida como sendo um processo, pois acompanha o curso de vida do jovem. Em sua análise contemplam-se aspectos individuais, institucionais e sócio-históricos. Por individuais compreendem-se a origem familiar, as representações do trabalho, as experiências e as expectativas com o trabalho, e as estratégias de inserção. Os elementos institucionais envolvem a análise das organizações profissionais, dos agentes intermediários (tais como as agências terceirizadas e as empresas de recrutamento e seleção), as políticas públicas, as políticas de Recursos Humanos, e as regulamentações estatais. Já os elementos sócio-históricos englobam a análise da conjuntura ecônomica, os níveis de formação da mão-de-obra, o desenvolvimento tecnológico e industrial e a estrutura demográfica e ocupacional.

Logo, ressalta-se que a inserção profissional é "um processo individual, coletivo, histórico e socialmente inscrito" (ROCHA-DE-OLIVEIRA; PICCININI, 2012b, p. 49). Individual por se referir as experiências, escolhas e expectativas profissionais de cada um; coletivo por apresentar semelhança para um grupo geracional ou para determinado grupo profissional; histórico por acontecer ao longo da vida ou por um período, sob influência de elementos de

Perspectivas em Gestão \& Conhecimento, João Pessoa, v. 9, n. 3, p. 81-101, set./dez. 2019. 
tempo e espaço ("políticas públicas, mercado de trabalho, organização do sistema de ensino e políticas de recursos humanos e os pontos de vista 'empresariais' sobre as relações entre educação e trabalho") (p.49). Socialmente inscrito porque ocorre em determinado "contexto socioeconômico e cultural, em que, além dos elementos institucionais, há influência das construções e das representações sociais" da inserção profissional (p. 49).

A inserção profissional, portanto, é considerada como um problema social, não-linear e não padronizado. Corroborando, Volkmer Martins (2016, p. 69) salienta que a inserção "resulta de inúmeras e complexas interações", por isso a necessidade de vê-la como um processo sócio-histórico, situada tanto em um micro-ambiente, em regiões de um mesmo país, em um ambiente de maior complexidade, ou até mesmo numa comparação entre países. Busca-se realizar uma análise ponderada entre o sistema de ensino, as relações de trabalho e as relações industriais nas realidades observadas.

Depreendendo-se que a inserção é evidente para grupos sociais distintos bem como para grupos juvenis diversificados, pode-se dizer que ela é um "processo multifacetado [...] e que apreende elementos materiais e simbólicos na relação entre eles" (VOLKMER MARTINS, 2016, p. 81). Sobretudo, entende-se a juventude como um "grupo diverso, ou múltiplas juventudes que sofrem influência do contexto histórico em que cresceram" que possuem "modos de pensar, de agir e de viver o processo de passagem à vida adulta e que, por consequência, vivem modos distintos de inserção profissional" (ROCHA-DE-OLIVEIRA; PICCININI, 2012a, p. 69-70).

Relativo ao contexto social, Tartuce (2007) salienta que os indivíduos melhores posicionados na pirâmide social tendem a manter o seu status social, enquanto que aqueles mais abaixo dessa pirâmide sofrem muito mais as consequências do desemprego e da precariedade, como os seus contextos socioeconômicos e culturais delineiam o seu ciclo de vida e sua transição para o mercado de trabalho.

Para Rocha-de-Oliveira e Piccinini (2012a) a inserção do jovem no mercado de trabalho possui três características: a posse do diploma como uma diferenciação social; a adaptação ao emprego sob responsabilidade do Estado, do próprio jovem e de sua família; e a busca por atividades profissionais como resposta à exigência por comprovação de experiências.

Já Lemos, Neves e Rodrigues (2013) trazem a perspectiva de Bourdieu quanto aos capitais. Para os autores, no processo de inserção profissional existem três tipos de capitais: a. econômico, referindo-se aos bens e às finanças do trabalhador; b. cultural, formado pela incorporação de novas culturas, idiomas e a obtenção do diploma universitário; c. e social, composto pelas redes de relacionamento, em extensão e qualidade.

Por fim, Volkmer Martins (2016) ressalta a importância de se falar sobre o rebaixamento social (ou déclassement) intrínseco ao processo de inserção profissional. Para a autora o rebaixamento social pode estar associado ao

[...] rebaixamento intergeracional (quando os filhos se encontram numa situação menos favorável que os pais), o rebaixamento de diplomados (quando o diploma ocupa uma vaga de emprego inferior à sua qualificação) e o [...] rebaixamento durante o ciclo de vida (quando um acontecimento abrupto provoca uma degradação das condições de vida) (VOLKMER MARTINS, 2016, p. 79).

Ainda, é oportuno citar Peugny (2014), que analisou a França sob a ótica do déclassement. Para o autor, a expressividade do rebaixamento social desde o fim de 1970 "[...] conduz à precarização crescente das condições de vida de diversas parcelas da população" e "os debates sobre o rebaixamento surgem para questionar a posição das classes médias no espaço social, as quais, por sua vez, estariam desestabilizadas" (PEUGNY, 2014, p. 39-40).

Perspectivas em Gestão \& Conhecimento, João Pessoa, v. 9, n. 3, p. 81-101, set./dez. 2019. 
Peugny (2014) salienta ainda que é na colocação profissional do indivíduo, seja ele de origem de pais operários, seja de pais executivos, que se percebem as situações de rebaixamento.

\section{METODOLOGIA}

Este estudo apresenta uma revisão bibliométrica sobre a produção científica no campo da inserção profissional nos estudos brasileiros. Por pesquisas bibliométricas entendem-se os estudos orientados a analisar aspectos quantitativos da produção acadêmica (MACIASCHAPULA, 1998), bem como para a avaliação das características, autores, instituições, entre outros, dos estudos em determinada área do conhecimento (HAYASHI et al., 2005). Para tanto apresenta-se dois momentos: o primeiro, de caráter descritivo e quantitativo sobre a produtividade científica; e no segundo momento expressa-se uma análise qualitativa, objetivando explorar os conteúdos das publicações analisadas.

As buscas foram realizadas em cinco bases de dados: Scientific Periodicals Electronic Library (SPELL), Scientific Electronic Library Online (SciELO), EBSCO, Periódicos Eletrônicos de Psicologia (PePSIC) e CAPES. A decisão pelo uso dessas bases de dados para fins de busca e seleção das publicações na temática decorreu do entendimento e da percepção de que elas se configuram como plataformas comuns de pesquisa na Administração, especialmente SPELL, SciELO, EBSCO e CAPES, esta última representando uma política pública de subsídio de acesso ao conhecimento científico gerido por uma agência de fomento brasileira (Coordenação de Aperfeiçoamento de Pessoal de Nível Superior - CAPES) e se constituindo como "um dos maiores acervos mundiais [...] e atualmente o principal mecanismo para o apoio bibliográfico às atividades de C,T\&I no Brasil" (ALMEIDA et al., 2010, p. 220). A pesquisa foi conduzida entre os meses de agosto e dezembro de 2017 e utilizou como estratégia de busca de artigos as seguintes palavras-chave: "Jovem AND Inserção profissional"; "Jovem AND Mercado de trabalho"; "Jovem AND Trabalho"; "Juventude AND Inserção profissional"; "Juventude AND Mercado de trabalho"; "Juventude AND Trabalho".

Foram incluídos apenas artigos científicos completos e artigos de revisão completos publicados em qualquer tempo, sendo analisados os títulos e resumos desses artigos. Em contrapartida foram excluídos do estudo artigos duplicados, monografias, dissertações, teses, livros e aqueles que não se relacionavam diretamente ao tema.

Relativo à etapa de seleção dos artigos, primeiramente se analisou os títulos e os resumos. Posteriormente, sobre os artigos selecionados proferiu-se a leitura na íntegra, evidenciando, na etapa quantitativa, a) o tempo de publicação, b) os periódicos e os respectivos Qualis, c) as universidades e d) os pesquisadores que publicaram no tema, e e) os métodos empregados nos estudos. Na etapa qualitativa, foram investigados a) o uso da teoria de inserção profissional, b) os objetivos das pesquisas e c) os principais resultados obtidos das publicações.

\section{APRESENTAÇÃO E DISCUSSÃO DOS RESULTADOS}

\subsection{Total de artigos identificados nas bases de dados}

Uma busca preliminar nas bases dados apontou 571 artigos que possuíam relação com o tema, mais especificamente: SPELL (67 artigos), SciELO (234 artigos), EBSCO (89 artigos), PePSIC (94 artigos) e CAPES (87 artigos). Quanto aos artigos em duplicata, foram registrados 116 estudos, sendo 33 (SPELL), 24 (SCIELO), 28 (EBSCO), 8 (PePSIC) e 29 (CAPES). A maioria dos trabalhos encontrados abordavam inserção como inclusão, focando em grupos considerados excluídos do mercado de/no mercado de trabalho e não na abordagem como processo de passagem do sistema de formação para o trabalho. Assim, do total dos estudos registrados,

Perspectivas em Gestão \& Conhecimento, João Pessoa, v. 9, n. 3, p. 81-101, set./dez. 2019. 
foram excluídos aqueles com uma orientação de análise de inserção como inclusão e os repetidos. Para a segunda etapa 51 estudos foram considerados válidos: quatro artigos da base SPELL, 22 artigos da SciELO, três artigos da PePSIC e 22 artigos do portal de periódicos CAPES. Nenhum artigo da base de dados EBSCO atendeu ao tema e aos critérios estabelecidos na pesquisa.

\subsection{Cronologia das publicações}

A contagem da produção acadêmica foi organizada em quadriênios. Os quadriênios mais expressivos em termos de publicação foram 2010-2013 (19 artigos) e 2014-2017 (19 artigos). Importante destacar que a publicação entre 1998 e 2005 não ocorreu de forma regular, pois foram observadas lacunas de publicação no período citado, conforme o Quadro 1.

Quadro 1 - Cronologia das publicações

\begin{tabular}{cccccc}
\hline Ano & $\begin{array}{c}\text { No } \\
\text { publicações }\end{array}$ & $\begin{array}{c}\text { Percentual } \\
(\mathbf{\%})\end{array}$ & Ano & $\begin{array}{c}\text { No } \\
\text { publicações }\end{array}$ & $\begin{array}{c}\text { Percentual } \\
\text { (\%) }\end{array}$ \\
\hline $\mathbf{1 9 9 8}$ & 1 & 1,9 & $\mathbf{2 0 1 0}$ & 5 & 9,6 \\
\hline $\mathbf{2 0 0 1}$ & 1 & 1,9 & $\mathbf{2 0 1 1}$ & 4 & 7,7 \\
\hline $\mathbf{2 0 0 2}$ & 1 & 1,9 & $\mathbf{2 0 1 2}$ & 5 & 9,6 \\
\hline $\mathbf{2 0 0 5}$ & 1 & 1,9 & $\mathbf{2 0 1 3}$ & 5 & 9,6 \\
\hline $\mathbf{2 0 0 6}$ & 2 & 3,8 & $\mathbf{2 0 1 4}$ & 4 & $\mathbf{7 , 7}$ \\
\hline $\mathbf{2 0 0 7}$ & 3 & 5,8 & $\mathbf{2 0 1 5}$ & 4 & $\mathbf{7}$ \\
\hline $\mathbf{2 0 0 8}$ & 3 & 5,8 & $\mathbf{2 0 1 6}$ & 6 & 11,5 \\
\hline $\mathbf{2 0 0 9}$ & 2 & 3,8 & $\mathbf{2 0 1 7}$ & 5 & 9,6 \\
\hline & & Fonte: dados da pesquisa (2018) &
\end{tabular}

\subsection{Publicações em periódicos}

Neste estudo foram identificados 39 periódicos nos quais trabalhos sobre inserção profissional foram publicados. De acordo com o Quadro 2 é possível identificar o QUALIS de tais periódicos, sendo um (01) periódico $A 1(2,56 \%)$, quatro $A 2(10,24 \%), 13$ periódicos B1 $(33,28 \%), 10$ periódicos B2 (25,6\%), 2 Qualis Capes B3 (5,12\%), cinco periódicos B4 (12,8\%) e três periódicos Qualis Capes B5 (7,68\%).

Quadro 2 - Publicações em periódicos conforme o Qualis CAPES (2013-2016)

\begin{tabular}{|c|c|c|}
\hline Periódico & Qualis & Observação \\
\hline Educação e Sociedade & A1 & Periódico da Educação \\
\hline Cadernos CEDES & $\mathrm{A} 2$ & Periódico da Sociologia \\
\hline Estudos Avançados & $\mathrm{A} 2$ & \\
\hline Revista electrónica de enseñanza de las ciencias & $\mathrm{A} 2$ & Periódico Interdisciplinar \\
\hline Saúde e Sociedade & $\mathrm{A} 2$ & \\
\hline Administração: Ensino e Pesquisa & B1 & \\
\hline Caderno CRH & B1 & \\
\hline Educação e Pesquisa & B1 & \\
\hline Mediações: Revista de Ciências Sociais & B1 & Periódico da Sociologia \\
\hline Política e Trabalho & B1 & Periódico da Sociologia \\
\hline Revista Administração Mackenzie & B1 & \\
\hline Revista Brasileira de Estudos de População & B1 & \\
\hline Revista de Ciências da Administração & B1 & \\
\hline $\begin{array}{l}\text { Revista Faculdad de Ciencias Económicas: Investigación y } \\
\text { Reflexión }\end{array}$ & B1 & \\
\hline
\end{tabular}

Perspectivas em Gestão \& Conhecimento, João Pessoa, v. 9, n. 3, p. 81-101, set./dez. 2019. 


\begin{tabular}{lll}
\hline Revista Katálysis & B1 & Periódico da Sociologia \\
\hline Revista Psicologia Organizações e Trabalho & B1 & \\
\hline Sociologia & B1 & Periódico da Sociologia \\
\hline Tempo Social & B1 & \\
\hline Arquivos Brasileiros de Psicologia & B2 & \\
\hline Psicologia e Sociedade & B2 & \\
\hline Psicologia: Ciência e Profissão & B2 & \\
\hline Revista Brasileira de Estudos Pedagógicos & B2 & \\
\hline Revista Científica Hermes & B2 & \\
\hline Revista latinoamericana de Ciencias Sociales, Niñez y juventud & B2 & \\
\hline Revista Pensamento Contemporâneo em Administração & B2 & \\
\hline Revista Portuguesa de Educação & B2 & \\
\hline Trabalho, Educação e Saúde & B2 & \\
\hline Ultima década & B2 & Periódico Interdisciplinar \\
\hline Conjectura: filosofia e educação & B3 & \\
\hline Revista Brasileira de Desenvolvimento Regional & B3 & \\
\hline Eventos pedagógicos & B4 & Periódico da Sociologia \\
\hline Polis (Santiago) & B4 & \\
\hline Revista Electrónica Direito e Sociedade & B4 & Periódico da Sociologia \\
\hline Revista Espaço & B4 & \\
\hline Revista Labor & B4 & \\
\hline Barbaroi & B5 & Periódico da Sociologia \\
\hline Interfaces da Educação & B5 & Periódico da Sociologia \\
\hline Revista UniVap & B5 & Periódico da Sociologia \\
\hline
\end{tabular}

Fonte: dados da pesquisa (2018)

O reconhecimento dos periódicos onde tais publicações são veiculadas é o motivo para se proferir essa análise. Assim, foram identificados 40 periódicos que possuem pelo menos uma publicação sobre o tema. Desses, apenas sete possuem entre dois e três artigos publicados, os quais são destacados: Última Década, Tempo Social, Revista Katálysis e Psicologia \& Sociedade (todos com duas publicações); e Caderno CRH, Psicologia: Ciência e Profissão, Revista Brasileira de Estudos de População e Revista Latinoamericana de Ciencias Sociales, Niñez y Juventud (todas essas com três artigos). Em contrapartida, os demais 33 periódicos possuem somente um trabalho publicado, segundo o Quadro 3 abaixo. Nota-se uma dispersão de publicação em vários periódicos, sem que haja um periódico central ou foco de publicações.

Quadro 3 - Identificação dos periódicos em que os artigos foram publicados

\begin{tabular}{lccc}
\hline \multicolumn{1}{c}{ Periódico } & $\begin{array}{c}\text { No } \\
\text { absoluto }\end{array}$ & $\begin{array}{c}\text { Percentual } \\
(\%)\end{array}$ & Anos de publicação \\
\hline Caderno CRH & 3 & 5,8 & 2007,2013 \\
\hline Psicologia: Ciência e Profissão & 3 & 5,8 & $2006,2007,2010$ \\
\hline Revista Brasileira de Estudos de População & 3 & 5,8 & 2008,2016 \\
\hline $\begin{array}{l}\text { Revista 87atino-americana de Ciencias Sociales, } \\
\text { Niñez y juventud }\end{array}$ & 3 & 5,8 & $2008,2012,2016$ \\
\hline Última década & 2 & 3,8 & 2009,2016 \\
\hline Tempo Social & 2 & 3,8 & 2001,2005 \\
\hline Revista Katálysis & 2 & 3,8 & 2009,2016 \\
\hline Psicologia e Sociedade & 2 & 3,8 & 2008,2010 \\
\hline Demais periódicos & 33 & 62,7 & $1998-2017$ \\
\hline
\end{tabular}

Perspectivas em Gestão \& Conhecimento, João Pessoa, v. 9, n. 3, p. 81-101, set./dez. 2019. 


\subsection{Universidades envolvidas}

Fonte: dados da pesquisa (2018)

Ao todo foram 42 instituições de ensino superior que apresentaram pelo menos um trabalho produzido no campo da inserção profissional. Dessas, ganham destaque quatro instituições: UFRGS (quatro artigos), UNIVALI, UFRJ e USP (essas três últimas com dois trabalhos cada), conforme o Quadro 4.

Quadro 4-Universidades com maiores números de publicações no tema

\begin{tabular}{|c|c|c|c|}
\hline Instituição & $\begin{array}{c}\text { № } \\
\text { absoluto }\end{array}$ & $\begin{array}{c}\text { Percentual } \\
\text { (\%) }\end{array}$ & $\begin{array}{c}\text { Anos de } \\
\text { publicação }\end{array}$ \\
\hline Universidade Federal do Rio Grande do Sul (UFRGS) & 4 & 7,7 & $\begin{array}{c}2006,2010, \\
2012\end{array}$ \\
\hline Universidade do Vale do Itajaí (UNIVALI) & 2 & 3,8 & 2008,2017 \\
\hline Universidade Federal do Rio de Janeiro (UFRJ) & 2 & 3,8 & 2011,2013 \\
\hline Universidade de São Paulo (USP) & 2 & 3,8 & 2001,2017 \\
\hline Outras instituições & 42 & 79,8 & 1998-2017 \\
\hline
\end{tabular}

Fonte: dados da pesquisa (2018)

Analisou-se também os periódicos em que as instituições mais publicam. Quanto ao QUALIS dos periódicos, a UFRGS possui dois artigos B2 e duas publicações B1. A UNIVALI possui duas publicações B2; e as ambas as instituições UFRJ e USP apresentam um trabalho Qualis B1 e outro Qualis B2 (Quadro 5).

Quadro 5 - Periódicos por instituição de ensino

\begin{tabular}{ccc}
\hline Instituição & $\begin{array}{c}\text { No } \\
\text { absoluto }\end{array}$ & Periódicos \\
\hline $\begin{array}{c}\text { Universidade Federal do Rio Grande } \\
\text { do Sul (UFRGS) }\end{array}$ & 4 & $\begin{array}{c}\text { Psicologia: Ciência e Profissão, Revista } \\
\text { Administração Mackenzie, Revista Ciências da } \\
\text { Administração, Revista Pensamento } \\
\text { Contemporâneo em Administração }\end{array}$ \\
\hline $\begin{array}{c}\text { Universidade do Vale do Itajaí } \\
\text { (UNIVALI) }\end{array}$ & 2 & $\begin{array}{c}\text { Psicologia e Sociedade, Revista Brasileira de } \\
\text { Estudos Pedagógicos }\end{array}$ \\
\hline $\begin{array}{c}\text { Universidade Federal do Rio de } \\
\text { Janeiro (UFRJ) }\end{array}$ & 2 & Arquivos Brasileiros de Psicologia, Caderno CRH \\
\hline $\begin{array}{c}\text { Universidade de São Paulo (USP) } \\
\text { Outras instituições }\end{array}$ & 2 & Revista latinoamericana de Ciencias Sociales, Niñez \\
y juventud, Tempo Social
\end{tabular}

Fonte: dados da pesquisa (2018)

\subsection{Método de pesquisa}

Em relação ao método de pesquisa, dos 51 artigos analisados, 35 deles são qualitativos $(68,6 \%)$, nove são quantitativos $(17,64 \%)$ e cinco utilizam os dois métodos (quali-quanti, $9,8 \%)$. Não foram incluídos dois artigos, pois foram classificados como teóricos (revisões bibliográficas), como pode-se ver no Quadro 6.

\begin{tabular}{ccc}
\multicolumn{3}{c}{ Quadro 6-Tipos de estudos (metodologia) } \\
\hline & Frequência & Porcentagem (\%) \\
\hline Quali-quanti & 5 & 9,80 \\
\hline Qualitativo & 35 & 68,60 \\
\hline
\end{tabular}

Perspectivas em Gestão \& Conhecimento, João Pessoa, v. 9, n. 3, p. 81-101, set./dez. 2019. 


\begin{tabular}{ccc}
\hline Quantitativo & 9 & 17,64 \\
\hline Teórico & 2 & 3,92 \\
\hline Total & 52 & 100,0 \\
\hline
\end{tabular}

Fonte: dados da pesquisa (2018)

\subsection{Autores principais e secundários}

No geral, 98 autores desenvolveram trabalhos no campo da inserção, estando 49 desses em primeira autoria e os outros 49 pesquisadores como secundários. Quanto aos autores principais, pelo menos um trabalho acerca da inserção profissional foi publicado. Contudo, apenas dois deles se destacam: Sidinei Rocha de Oliveira (com três artigos) e Adalberto Cardoso (dois artigos). Sobre os autores secundários, somente a autora Valmiria Carolina Piccinini está presente em duas publicações, todos os demais participaram em apenas uma publicação.

Quadro 7 - Autores que mais produziram na temática

\begin{tabular}{lccc}
\hline \multicolumn{1}{c}{ Autor principal } & № de artigos & Percentual (\%) & Anos de publicação \\
\hline Sidinei Rocha de Oliveira & 3 & 5,8 & 2010,2012 \\
\hline Adalberto Cardoso & 2 & 3,8 & 2013 \\
\hline Demais autores (47) & 1 & 89,30 & $1998-2017$ \\
\hline
\end{tabular}

Fonte: dados da pesquisa (2018)

\subsection{Objetivos dos estudos}

Partindo-se a uma análise qualitativa das publicações pode-se considerar que os objetivos dos 51 artigos analisados estão concentrados em quatro áreas: a) aspectos sociais (individuais e coletivos), históricos e econômicos da inserção profissional; b) políticas públicas voltadas ao processo de inserção; c) análise de documentações governamentais e de órgãos regulamentadores; d) e expectativas, identidades pessoais e profissionais dos indivíduos sobre o processo de inserção profissional.

Sobre o primeiro aspecto, inserção e sua construção sócio-histórica e econômica, alguns estudos mais teóricos são evidenciados, os quais propõem conceituar inserção profissional, propor um modelo analítico e uma agenda de pesquisa brasileira (CARDOSO, 2010; ROCHA-DE-OLIVEIRA, 2012). No que se refere a verificar padrões históricos de inserção em períodos de estagnação econômica destaca-se o trabalho de Santos e Gimenez (2015). Já Soto (2009) busca relacionar as novas formas de se compreender a juventude com as transformações históricas do trabalho a partir do século XX.

Ainda nesse bojo, os estudos buscaram suscitar a percepção de jovens trabalhadores quanto às mudanças organizacionais e tecnológicas no processo produtivo e a consequência sobre o seu trabalho (MARTINS, 2001). Nota-se um conjunto de trabalhos voltados a analisar o emprego e a juventude: Guilland e Monteiro (2010) revisam a literatura nacional e a internacional sobre o desemprego juvenil. Gonçalves et al. (1998) e Nunes (2015) focam na análise conceitual do emprego e desemprego no Brasil sob o fenômeno da oferta e da procura por trabalho pelos jovens; Cadona e Góes (2013) buscam compreender a situação do emprego e do desemprego em um ambiente de precarização do mercado de trabalho juvenil no Brasil e Silva, Queiroz e Cariri (2015) analisam a evolução do mercado de trabalho e o processo de transição/inserção dos jovens ao longo dos anos.

A importância da educação em seus diferentes níveis também foi um ponto de destaque. Dentre os contextos em que ela foi retratada aponta-se a relação entre juventude e escolarização, suscitando reflexões sobre as razões para a permanência nos estudos e as

Perspectivas em Gestão \& Conhecimento, João Pessoa, v. 9, n. 3, p. 81-101, set./dez. 2019. 
causas do abandono escolar em nível profissional, embasando-se nos conceitos de juventude, escola e trabalho (SILVA; PELISSARI; STEIMBACH, 2012); a relevância da educação na transição para a vida adulta e a noção de juventude pelo viés social e analítico (PEREGRINO, 2011).

Essa discussão também surge em estudos que evidenciaram as experiências de jovens periféricos brasileiros na educação não-formal (LARANJEIRA; TEIXEIRA; BOURDON, 2007); as estratégias de conciliação entre trabalho, educação e família por jovens cursistas do ensino noturno no ensino público secundário (RAITZ; PETTERS, 2008; SANTOS; CUNHA, 2013); a análise de padrões nas atividades profissionais e do processo de aprendizagem e preparação do jovem para o ingresso no mercado (CALDERÓN et al., 2016). Explorando a relação entre trabalho, educação e políticas públicas, Costa (2014) buscou articular ensino superior, trabalho e juventude sob a ótica de programas governamentais de acesso à Educação (PROUNI) e Nakano et al. (2007) propuseram reflexões sobre o acesso à Educação reforçando a necessidade da elevação da qualidade do ensino como estratégia de enfraquecimento de reproduções sociais.

Ainda, alguns estudos centraram as investigações com estudantes e egressos em contextos profissionais e sociais diversificados em três vertentes. A primeira volta-se para o processo de inserção em campos específicos como a de transição de jovens formados e as trajetórias profissionais constituídas (SOUZA, 2012), as vivências de grupos específicos na transição para o mercado de trabalho (MELO; BORGES, 2007), a análise da inserção a partir das experiências de estudantes de Administração em estágios nas organizações (ROCHA-DEOLIVEIRA; PICCNINI, 2012); análise da inserção dos egressos de cursos de licenciatura (MARQUES, 2017) e a relação do ingresso com a proposta de uma formação interdisciplinar e interprofissional (CANDIDO; ROSSIT; OLIVEIRA, 2017).

Na seguna vertente, focada em jovens com dificuldade de inserção, são analisados a relação dos jovens com o trabalho em redes de restaurante fastfood entre 2000 e 2007 (AREND; REIS, 2009); os impasses da inserção e seus impactos na subjetivação de jovens com idade entre 16 e 24 anos no primeiro emprego e a existência ou não de dificuldades na inserção (WICKERT, 2006; GARCIA et al., 2011) e os significados, trajetórias e as estratégias iniciais dos jovens entre 18 e 24 anos, em situação de vulnerabilidade psicossocial, na construção da carreira e tutelados por agências de emprego (RIBEIRO, 2011), a inserção a partir dos movimentos sociais de afirmação dos direitos humanos na América Latina através das experiências de jovens e operários participantes desses movimentos estudantis (EUFRASIO, 2014).

A terceira vertente volta-se para uma análise de orientação psicológica do processo de inserção, como a investigação da autopercepção dos jovens sobre a sua atuação no mercado, a sua percepção sobre o acesso e as razões para trabalhar (MUNIZ; MEDEIROS, 2015); a análise do adiamento do ingresso pelo método singulate mean age e pelas tabelas de sobrevivência (TOMÁS; OLIVEIRA; RIOS-NETO, 2008); as expectativas com o primeiro emprego e os níveis de empregabilidade dos egressos de acordo com o Guia de Profissões e Mercado de Trabalho (LEITE; MOREIRA, 2010); as expectativas dos discentes dos cursos de licenciatura sobre a escolha profissional e a inserção no mercado (OSTROVSKI; SOUSA; RAITZ, 2017). Também, Oliveira, Golgher e Loureiro (2016) buscaram trabalhar as impressões dos jovens sobre a saída da casa dos pais e da escola e a entrada no mercado de trabalho, observando a aceleração das transições para a vida adulta no período de bom desempenho econômico entre 2003 e 2011 no país.

Em relação às políticas públicas, alguns estudos propuseram a análise de políticas de emprego que atuem na construção juvenil para o trabalho (AVELLA, 2008; AGUILERA, 2016); políticas públicas voltadas para público jovem "nem-nem" suscitando tendências, mudanças e hipóteses para essa condição (CARDOSO, 2013); políticas públicas educacionais concentradas na preparação e na aprendizagem dos jovens para o ingresso no trabalho (RAZA; LALLI, 2013;

Perspectivas em Gestão \& Conhecimento, João Pessoa, v. 9, n. 3, p. 81-101, set./dez. 2019. 
DALAROSA; SOUZA, 2014) e na formação e continuidade profissional de estudantes de licenciatura bolsistas e integrantes de projetos educacionais, como o PIBID (GOBBO; AMBROSETTI, 2017); a atuação de agentes institucionais para a população jovem periférica referente aos saberes intergeracionais, através de atividades lúdicas e culturais (NEVES, 2006); as redes de cooperação internacionais e sua relação com agentes locais na promoção de discussões e estratégias para a inserção sociolaboral dos jovens (GIRARDO; SILES, 2012); e a análise dos programas sociais de capacitação e inserção nos países da América Latina desde 1990 (DORNELLES; PANOZZO; REIS, 2016).

Os trabalhos que focaram a análise de documentos oficiais circundaram a situação social e laboral dos jovens em um período de fim do boom econômico e crise econômica, refletindo sobre as possibilidades de redução das desigualdades de acesso ao emprego (LUCAS; BALIBREA, 2016; SIMÕES; ALVES; SILVA, 2016); e a análise dos dados de uma pesquisa do setor industrial automobilístico da região do $A B C$ paulista, comparando jovens com idade entre 19 e 29 anos e o perfil socioeconômico dos demais trabalhadores com 30 anos ou mais de idade (RODRIGUES; MARTINS, 2005).

No âmbito da formação das identidades, os estudos investigaram o processo de construção de identidades profissionais no contexto da formação profissional (OLIVEIRA, 2017); a identidade pessoal juvenil na primeira inserção e o processo de exclusão social (ROCHA; GÓIS, 2010); a construção de identidades dos jovens no trabalho e nas relações sociais, considerando a existências de múltiplas juventudes e as transformações do conceito de juventude em diferentes contextos e formas do emprego na contemporaneidade (MERCHÁN; GARCÍA, 2014); a identidade social, as representações sociais sobre o trabalho para os jovens do ensino secundário da rede pública de ensino (JEOLÁs; LIMA, 2002); as representações sociais e a compreensão sobre o que é trabalho (ROCHA-DE-OLIVEIRA; PICCININI, 2010); a construção de trajetórias, narrativas e projetos em um cenário de novas configurações do trabalho (MAIA; MACHADO, 2010); as representações sociais de universitários surdos na inserção e nas relações sociais que constituem, sob a perspectiva da teoria das representações sociais (MAGALDI; LIMA, 2017).

O conjunto dos trabalhos aponta que os estudos sobre inserção profissional seguem diferentes vertentes e focos de análise com poucos autores que busquem discutir o fenômeno de modo sistematizado ao longo do tempo. $O$ isolamento dos objetivos e a falta de continuidade de grupos de pesquisadores no desenvolvimento do tema pouco contribui para o amadurecimento teórico e avanços na discussão e nos métodos de pesquisa, fazendo com que cada estudo tenha uma contribuição limitada para o tema.

\subsection{Principais resultados das publicações}

Da leitura e análise dos resultados das publicações percebem-se dois enfoques principais: o olhar sobre as experiências de estágio e o primeiro emprego dos jovens; e a retratação dos diferentes aspectos que circundam o processo de inserção profissional, como destacam Rocha-de-Oliveira e Piccinini (2012): individuais, institucionais e sócio-históricos.

Por uma questão de extensão das análises passa-se a relatar, neste momento, sobre a temática dos estágios e do primeiro emprego. Nesse âmbito, as publicações destacam que a realização de estágios reflete a busca por conhecimentos e a independência financeira; assim como não podem ser caracterizados como uma iniciativa com motivações uniformes, pois considera-se uma juventude com trajetórias diversas (ROCHA-DE-OLIVEIRA; PICCININI, 2012). Melo e Borges (2007), a partir das entrevistas feitas com 20 jovens universitários, identificaram que existem semelhanças na inserção profissional em relação às experiências em estágios; e levantam uma discussão considerando uma visão realista do mercado de trabalho e um olhar crítico sobre o papel das universidades nesse momento decisivo na vida dos jovens.

Perspectivas em Gestão \& Conhecimento, João Pessoa, v. 9, n. 3, p. 81-101, set./dez. 2019. 
Por outro lado, o estudo de Rocha e Góis (2010) ressalta que o primeiro emprego pode dar sentido para a transição do jovem à vida adulta, emergindo um senso de poder e humanização; fala-se também dos paradoxos: ser revolucionário e ao mesmo tempo submisso, a autovalorização humana e o consumo, a realização profissional e pessoal em oposição ao sustento familiar. Essas contradições suscitam a precarização do trabalho e o lugar dos jovens nessa situação, estendendo-se a compreensão dos contextos quanto à vivência dos jovens no mercado de trabalho contemporâneo. De modo semelhante, Garcia et al. (2011) salientam que o crescimento ou a estagnação econômica tendem a deixar mais sensíveis as primeiras oportunidades de emprego. Os autores afirmam que nos últimos anos o primeiro emprego apresentou condição adversa no mercado de trabalho e, nesse quadro, políticas públicas são necessárias para a facilitação do acesso e perenidade do emprego para os jovens.

Em relação ao segundo eixo de resultados (aspectos da inserção profissional), os mesmos serão expostos na seguinte ordem: aspectos teóricos; individuais; institucionais; e sócio-históricos. O primeiro artigo teórico traz uma importante contribuição ao discutir o conceito de inserção, suscitando pontos de reflexão sobre os elementos que a constituem. Após uma vasta discussão, entende-se a inserção como uma construção sócio-histórica, em que há a articulação de características individuais, institucionais, socioeconômicas e culturais (ROCHA-DE-OLIVEIRA, 2012). Rocha-de-Oliveira e Piccinini (2010) salientam que o trabalho permite a integração social e as realizações pessoal, profissional e financeira, por isso é considerado uma centralidade na vida dos jovens.

Sobre os aspectos individuais da inserção, Wickert (2006) sustenta que o desemprego afeta a filiação social e tem efeitos sobre a produtividade e subjetividade do jovem trabalhador. A pesquisa de Ribeiro (2011) assegura que os significados do trabalho podem estar conectados à satisfação de demandas, assim, os sentidos das experiências de trabalho se dão pelo estabelecimento de relações sociais respeitosas (significado psicossocial) e pelo ganho financeiro (significado material). Contudo, as experiências naturalizam situações sócioocupacionais de conformidade e ausência de planejamentos futuros, devido à necessidade de responder a demandas presentes. Assim, cabe ao trabalhador o desenvolvimento e adaptação contínua no mercado, impactando na construção de carreiras em situações vulneráveis.

Maia e Machado (2010) apontam que as percepções, vivências e experiências relatadas pelos entrevistados acerca dos estágios promoveram uma construção social e um maior entendimento do perfil valorizado e reconhecido no mercado de trabalho vigente; os contatos (redes sociais) emergem como facilitadores para a inserção e permanência no mercado; e a abordagem da entrada na vida adulta contribuiu para a formação de um mosaico de oportunidades, despertando nos jovens uma trajetória intensa e com muitas transformações.

Ostrovski, Souza e Raitz (2017) retratam as expectativas durante o percurso da inserção profissional. Na ótica dos autores as expectativas são redobradas quando os jovens possuem o seu reconhecimento pela escolha profissional, porém, casos de baixo reconhecimento social da carreira e remuneração são fatores desmotivadores. Muniz e Medeiros (2015) discutem a empregabilidade no processo de inserção. Conforme os resultados de sua pesquisa, a lógica da empregabilidade cria um senso de individualidade e responsabilidade pela performance no mercado, assim também sendo um instrumento de realização e caraterização da sociedade contemporânea. A pesquisa de Marques (2017) desenvolvida com egressos do curso de Licenciatura em Física mostra que $64 \%$ deles atuam como professores e possuem como maiores desafios da profissão: a timidez, as dificuldades de relacionamento, a falta de condições materiais das escolas, o excesso de regulação externa e a perda da autonomia profissional. Além disso, dizem que as formas de enfrentamento a essas condições seguem pela via individual, sendo poucas as iniciativas ou culturas colaborativas e destacam a importância dos estágios e dos saberes pedagógicos em situações como essas.

Perspectivas em Gestão \& Conhecimento, João Pessoa, v. 9, n. 3, p. 81-101, set./dez. 2019. 
Considerando aspectos instituicionais, Lauer-Leite e Moreira (2010) evidenciam em seu estudo que a escolha do primeiro emprego tem como fundamento as relações interpessoais, em que fazem parte dessa decisão as diretrizes organizacionais, as relações com funcionários e as oportunidades de crescimento profissional; e as estratégias que visem a congruência entre os objetivos individuais e empresariais para a manutenção do jovem no trabalho. Silva, Pelissari e Steimbach (2012) salientam a busca por qualificação, onde afirmam que a procura crescente por cursos técnicos pelos jovens se dá em áreas que garantam a empregabilidade e certo status; por outro lado, ilusões são dissolvidas e o que mais se presencia são os problemas de permanência e abandono entre algumas experiências positivas. Reis (2009) mostrou que em restaurantes fastfood (ou de alimentação rápida) o trabalhador solicitado deve ser multifuncional, intercambiável e descartável, atuando em um ambiente de alta rotatividade e flexível (em termos de quantidade, lugar e tempo desejado). Lucas e Balibrea (2016) argumentam que as condições laborais estão cada vez mais precarizadas e interferem as possibilidades de estudo, formação e progresso social, o que se estende ao sistema de ensino como um todo, perpassando também pela exclusão social.

Nesse sentido, Oliveira (2017) discorre que ao longo da formação o jovem constroi tipos identitários, principalmente para o trabalho, prevalecendo dois tipos: identidade com a empresa e identidade com o ofício. Candido, Rossit e Oliveira (2017) podem corroborar ao relatarem as dificuldades de inserção dos profissionais de Educação Física no Sistema Único de Saúde (SUS). Os resultados da pesquisa apontam que apesar desses profissionais terem realizado um curso de graduação com ênfase no SUS, as taxas de inserção ainda não pequenas e menos frequentes.

Quanto aos estudos que abordam os aspectos institucionais da inserção Laranjeira, Teixeira e Bourdon (2007), Avella (2008), Cardoso (2013) e Aguillera (2016) destacam a necessidade reavaliação e investigação de legislação e de políticas que versem sobre as condições de emprego para esse grupo de jovens, com vistas a uma atuação sobre a juventude vulnerável e que garanta a empregabilidade e a autoestima. Focando aspectos da formação, Raitz e Petters (2008) concluíram que o papel das políticas públicas é fazer emergir propostas de educação e trabalho que atendam as condições dos jovens e contribuir para minimizar as incertezas do mercado de trabalho. Santos e Cunha (2013) falam das dificuldades de permanência no sistema escolar, e afirmam que tal problema tem com uma de suas causas o silêncio das escolas ou a sua inércia para enfrentar os problemas apresentados pelos jovens.

Siles (2012) aborda a exclusão social no processo de inserção reafirmando a importância da cooperação das organizações locais com as agências internacionais, reforçando a atuação efetiva desses organismos na realidade dos jovens. Dalarosa e Souza (2014) pesquisaram a educação profissional sob a ótica do capitalismo. Os resultados apontaram a necessidade de formação e capacitação profissional de jovens em todas as áreas de desenvolvimento, a fim de tornarem-se seres reflexivos e transformadores da realidade. Os autores indicam também a emergência de reformas educacionais que se voltem a um novo modelo de educação profissional, com melhores resultados e sob o controle da sociedade civil, contrapondo interesses do capital mundial e da classe empresária brasileira.

Analisando o Ensino Superior, Raza et al. (2013) apontaram que um dos problemas da inserção é o gap entre as universidades e o mercado de trabalho (a relação teoria e prática), ou seja, a falta da integração escolas-negócios-sociedade. Para tanto, os autores sugerem a adoção de políticas de estreitamento e preparação do jovem, visando a garantia do desenvolvimento social e econômico do país.

Os resultados da pesquisa de Costa (2014) sustentam, no âmbito do PROUNI, que para os jovens de baixa renda a educação superior assegura não só uma melhoria socioeconômica, mas uma possibilidade de maior mobilidade social, melhoria nas condições de vida, senso de pertencimento enquanto sujeito de direitos sociais, ampliação das relações sociais e a

Perspectivas em Gestão \& Conhecimento, João Pessoa, v. 9, n. 3, p. 81-101, set./dez. 2019. 
conquista de direitos negados. Rodrigues e Martins (2005) elucidam que há uma juventude heterogênea, onde se percebe jovens desempregados; em subempregos; e vivenciando um cenário de incertezas. Relacionando esse problema aos jovens metalúrgicos pesquisados, os autores dizem que esses últimos apresentam condições laborais superiores aos demais. Já Tomás, Oliveira e Neto (2008) observam o adiamento e uma alteração do padrão etário da inserção profissional, sendo mais saliente para os homens, apesar de sua entrada no mercado de trabalho acontecer mais cedo do que para as mulheres, como também menos jovens ingressantes no mercado até os 17 anos.

Em outra perspectiva, Souza (2012) aborda a baixa formação profissional ofertada pelas empresas, entendendo-a como decorrente dos poucos investimentos na profissionalização dos funcionários. Para o autor é essencial que se questione a qualidade do trabalho e os eventos decorrentes dele: a fraca mobilidade profissional e a incapacidade de alterar a sua situação. Souza (2012) expõe que essa situação está dispersa no tempo e tem como consequências a definição da origem social, as dificuldades de acesso ao emprego por diplomados, a sobrequalificação e a informalidade para muitos trabalhadores no primeiro emprego.

Por fim, destaca-se os estudos de cunho sócio-histórico. Na ótica de Martins (2001), as mudanças no trabalho somaram para a definição de um perfil trabalhador, em termos de escolaridade, formação profissional, participação e compromisso com os objetivos organizacionais; também, essas mudanças na estrutura do emprego possibilitaram a compreensão de uma juventude heterogênea. Segundo Mérchan e García (2014) a diversidade juvenil contribui para a quebra do entendimento da juventude como um grupo homogêneo, pois foi dada visibilidade para práticas emergentes em contextos juvenis específicos sob múltiplos olhares: trabalho, sensibilidades, utopias, reconhecimento, transitoriedades, sentido de unicidade, inclusão escolar, contexto de violência, redes institucionais e sociais onde esses jovens vivem.

O estudo de Simões, Alves e Silva (2016) mostra que nas metrópoles brasileiras houve uma redução da taxa de desocupação, vendo-se menor participação juvenil no mercado, menos escolarizados; e uma redução no ritmo da inserção feminina. Os autores temem pela emergência de uma "geração perdida". Também são oportunos os resultados da pesquisa de Dornelles, Panozzo e Reis (2016) que indicam a proliferação de trabalhos informais e sem proteção social; o aumento da taxa de desemprego e da instabilidade do emprego. Assim, os autores defendem parcerias ou propostas de agentes privados com a sociedade civil como medida de enfrentamento aos investimentos públicos pouco qualificados para atender a população juvenil. Sobre a pesquisa de Oliveira, Golgher e Loureiro (2016), os resultados evidenciam que entre 2003 e 2011 nas regiões metropolitanas do Brasil foi crescente o número de jovens que moram com os pais, principalmente para os homens com mais de 25 anos - em comparação ao período entre 1970 e 2000 . Também se notou uma diminuição no número de jovens estudantes e um aumento no número de jovens trabalhadores, apresentando um comportamento destoante daquele indicado em literatura.

A pesquisa de Santos e Gimenez (2015) investigou a situação dos jovens profissionais entre os anos 2004 e 2012 no Brasil (fase de crescimento econômico). Os resultados indicaram que nesse intervalo percebeu-se uma ampliação dos espaços de inserção, bem como a qualidade dos postos e a melhoria do emprego e da renda. Os bons resultados decorreram da diminuição da pressão pela entrada dos jovens no mercado de trabalho, vendo-se, a partir disso, um declínio na taxa de participação juvenil derivada da melhoria das condições familiares (emprego e renda) e o aumento de políticas públicas e menor pressão demográfica. Contudo, os autores salientaram que os anos posteriores poderiam indicar um mercado de trabalho juvenil em regressão. Esse temor tem respaldo nos resultados alcançados por Cadoná e Góes (2013), onde avaliaram que a inserção tem se tornado cada vez mais precária,

Perspectivas em Gestão \& Conhecimento, João Pessoa, v. 9, n. 3, p. 81-101, set./dez. 2019. 
interferindo na permanência do jovem no mercado e na construção de trajetórias profissionais formalizadas. Os autores destacam ser indispensáveis políticas de trabalho que amenizem os impactos da desestruturação dos mercados e da precarização, ambos sendo mais intensos para os jovens oriundos de famílias humildes.

Diante desses resultados, Guilland e Monteiro (2010) já diziam que o desemprego é influenciado pelo contexto social e, para compreender o jovem nessa situação, são essenciais pesquisas que analisem o seu processo de subjetivação. Para Nunes (2015) o desemprego é um dos maiores problemas do Brasil hoje, e se desenvolve entre o crescimento da população e a oferta e demanda de emprego. A autora analisa o universo sociocultural do desemprego e sugere que recursos federais sejam destinados a programas de criação de empregos para jovens; e propõe a compreensão de como as diferentes dimensões de família e escola interferem na performance dos jovens.

Peregrino (2011) analisou a estrutura juvenil brasileira ainda no período de crescimento econômico e identificou uma tendência a trabalhos não registrados; um aumento da procura por cursos de qualificação; e um fenômeno social para os jovens com menos recursos: escolarização em ambientes menores e pouco estruturados, proliferação de trabalhos manuais e domésticos (concomitantes ao ensino, muitas vezes), uma demanda de jovens sem experiências ou com pouca ou nenhuma capacitação. Em comparação aos jovens que circulavam mais em núcleos urbanos, os jovens em situação precária possuíam experiências e circulação mais restritos. Assim, Peregrino (2011) percebeu que existiam nuances dentro de grupos juvenis em situações precárias de inserção. Ou seja, o tipo de território que circulam permitem a eles experiências profissionais e trajetórias escolares mais efetivas. Porém, isso reforça novas desigualdades, a começar pela expansão da escola - do ensino médio e superior - a posição da escola na transição do jovem para a vida adulta, mais especificamente para jovens pobres. A expansão escolar amplia as condições de experimentação juvenil.

Paz-Calderón et al. (2016) salientam que numa relação capital-trabalho as visíveis trocas e tendências no mercado mostram que a atuação dos jovens não acompanha a formação e a eles recaem a ocupação de funções destoantes de sua área, o que reduz as possibilidades de inserção em seu campo no mercado de trabalho.

Por fim, Magaldi e Lima (2017) expõem a luta histórica dos jovens surdos no campo do trabalho. Os resultados levantam significados na inserção de jovens surdos no mercado. Há duas posições de inserção: o entendimento dos surdos como deficientes em ambientes onde a comunicação é preponderante em língua portuguesa; e as culturas surdas, considerando o bilinguismo e um modelo antropológico, representando uma luta expressa no movimento social surdo por uma nova arquitetura educacional que possibilite a ocupação de espaços de poder predominantemente ouvinte.

Diante dos resultados aqui evidenciados e como forma de sintetizá-los, os estudos trouxeram perspectivas de análises que versaram sobre as experiências de estágio e seus desdobramentos (primeiro emprego, busca por conhecimentos, independência financeira); sobre a realização profissional e o senso de autovalorização; o papel das universidades, das políticas públicas e das organizações na condução de jovens e jovens universitários em suas trajetórias profissionais e de vida; a formação de identidades para o trabalho; a proliferação de trabalhos informais e a falta de proteção social, bem como sobre desemprego e instabilidade no mercado de trabalho em relação aos jovens. Além desses resultados, outras pesquisas concentraram seus esforços sobre as desigualdades sociais e profissionais; a mobilidade social; a estrutura socioeconômica juvenil no Brasil; e inclusão, retratando a luta histórica dos jovens surdos no campo do trabalho. Observa-se uma grande dispersão de temas e focos de estudo com o predomínio da atenção sobre jovens em situação de vulnerabilidade e poucos estudos

Perspectivas em Gestão \& Conhecimento, João Pessoa, v. 9, n. 3, p. 81-101, set./dez. 2019. 
voltados para a compreensão do ingresso dos egressos do ensino superior no mercado de trabalho.

\section{CONSIDERAÇÕES FINAIS}

O artigo teve por objetivo apresentar uma revisão bibliográfica sobre o tema inserção profissional, pesquisando a produção acadêmica brasileira em cinco bases de dados, não sendo delimitado o tempo de publicação dos trabalhos. Antes se procedeu a uma fundamentação teórica sobre o tema, como estratégia de ambientação do leitor ao assunto e ao conceito de inserção adotado.

As bases de dados científicas que embasaram este estudo foram SPELL, SciELO, EBSCO, PePSIC e CAPES, uma vez que representam no campo da Administração plataformas muito utilizadas como mecanismos de busca de artigos, dissertações, teses, dentre outros. Ao todo foram coletados 571 artigos que tangenciavam o tema de pesquisa, todavia, após a aplicação dos critérios de seleção dos estudos, foram analisados 51 artigos, assim distribuídos nas bases: SPELL (4), SciELO (22), PePSIC (3) e CAPES (22).

Em síntese, a etapa quantitativa do estudo evidenciou que a produção científica na temática foi mais evidente entre os anos de 2010 e 2017; a Universidade Federal do Rio Grande do Sul (UFRGS) foi a instituição de ensino mais representativa em publicações; e os métodos qualitativo e quantitativo predominaram enquanto estratégia metodológica. Apesar de ter a maior concentração, foram apenas três (3) estudos, número que confirma a dispersão de autores e instituições que trabalham sobre o tema.

De forma geral, na etapa qualitativa da pesquisa, notou-se que os trabalhos analisados, independente do ano de publicação ou do cenário socioeconômico que os circundam, problematizam a crise do mercado de trabalho e da educação, a juventude sob o olhar das desigualdades sociais e econômicas, as iniciativas privadas e públicas, especialmente políticas públicas educacionais e profissionais com atendimento prioritário à camada juvenil de baixa renda; e as identidades, expectativas e experiências profissionais.

Retratar a temática da inserção profissional, partindo de um esforço bibliométrico como o feito aqui, se torna oportuno uma vez que dá luz e reforça o empenho de pesquisadores a uma temática, de viés sociológico, sobre trajetórias profissionais e sociais possíveis entre os jovens do país em diferentes realidades socioprofissionais, destacando elementos que cruzam as esferas institucional e sócio-histórica. Assim, não se limita à individualidade, ou melhor, à autorresponsabilidade pelo desempenho das trajetórias no mercado de trabalho. Indo além, fala-se de um campo teórico-empírico instigante, no sentido do entendimento de uma juventude plural, onde se percebem diferentes desdobramentos sociais, econômicos, culturais, institucionais e históricos - podendo ser ao mesmo tempo representativo de um indivíduo e de uma coletividade.

Ainda, sente-se falta de um avanço no campo, isto é, estudos que renovem as perspectivas de entendimento ou que concentrem ainda mais seus esforços nas realidades investigadas. Sobretudo, percebe-se a possibilidade de associação da teoria de inserção francesa com outros quadros teóricos, pois ela permite analisar múltiplos grupos sociais.

Por fim, é fundamental dizer que este estudo não se propõe a esgotar o tema, mas contribuir para o avanço da produção científica na área e de novas lentes de análise. Ainda, tendo em vista a continuidade de estudos de caráter bibliométrico, sugere-se como pesquisas futuras o levantamento de artigos da literatura internacional, suas relações com pesquisas nacionais e análises e discussões sobre os cenários de pesquisa dos estudos; bem como uma sistematização continuada da produção brasileira no campo da inserção profissional.

Perspectivas em Gestão \& Conhecimento, João Pessoa, v. 9, n. 3, p. 81-101, set./dez. 2019. 


\section{REFERÊNCIAS}

AGUILERA, G. R. Gubernamentalidad y Políticas de empleo: La construcción discursiva del joven trabajador en Chile. Ultima década, v. 24, n. 45, p. 34-54, 2016.

ALMEIDA, Edler de et al. Dez anos do Portal de Periódicos da Capes: histórico, evolução e utilização. RBPG. Revista Brasileira de Pós-Graduação, v. 7, n. 13, 2010.

ALVES, C. L. B.; PAULO, E. M. Dinâmicas recentes do mercado de trabalho juvenil na região nordeste. In: MACAMBIRA, Júnior; ANDRADE, F. R. B. (Orgs.). Trabalho e Formação Profissional: Juventudes em Transição. Fortaleza: IDT, UECE, BNB, 2013, p. 205-230..

ALVES, N. Inserção Profissional dos Jovens: do problema social ao objecto sociológico. 2007. Disponível em: <http://www.uff.br/ejatrabalhadores/artigo-02.htm>. Acesso em agosto de 2017.

AMARAL, M. P. do; WALTHER, A. Juventude, educação e trabalho: teorizando a regulação de trajetórias educacionais e a transição escola-trabalho. In: MACAMBIRA, J.; ANDRADE, F. R. B. (Orgs.). Trabalho e Formação Profissional: Juventudes em Transição. Fortaleza: IDT, UECE, BNB, 2013, p. 15-35.

ARAÚJO, E. C. de et al. A condição do jovem no mercado de trabalho brasileiro: uma análise comparativa entre o emprego e o primeiro emprego (1999-2009). Revista Economia \& Tecnologia, v. 6, n. 4, 2010.

AREND, S. M. F.; REIS, A. M. D. Juventude e restaurantes fast food: a dura face do trabalho flexível. Revista katálysis, v. 12, n. 2, p. 142-151, 2009.

AVELLA, A. C. P. El mercado laboral de los jóvenes y las jóvenes de Colombia: realidades y respuestas políticas actuales. Revista Latinoamericana de Ciencias Sociales, Niñez y Juventud, v. 6, n. 2, 2008.

CADONÁ, M. A.; GÓES, C. H. Juventude e trabalho: emprego e desemprego entre jovens no município de Santa Cruz do Sul (RS). Barbarói, n. 39, p. 36, 2013.

CALDERÓN, Y. P. El papel del trabajo en la construcción del sujeto joven*/The role of labor in the construction of a youth subject/O papel do trabalho na construção do sujeito jovem. Revista Latinoamericana de Ciencias Sociales, Niñez y Juventud, v. 14, n. 2, p. 1303-1311, 2016.

CANDIDO, L. de O.; ROSSIT, R. Ap. S.; OLIVEIRA, R. C. de. Inserção profissional dos egressos de um curso de educação física com ênfase na formação em saúde. Trabalho, Educação e Saúde, v. 16, n. 1, p. 305-318, 2018.

CARDOSO, A. Juventude, trabalho e desenvolvimento: elementos para uma agenda de investigação. Caderno CRH, v. 26, n. 68, 2013.

CASTRO, J. A. de; ANDRADE, C. C. de. Juventude, educação e trabalho: avanços e desafios. 2013. In: MACAMBIRA, J.; ANDRADE, F. R. B. (Orgs.). Trabalho e Formação Profissional: Juventudes em Transição. Fortaleza: IDT, UECE, BNB, 2013, p. 155-168.

CATTANI, A. D. Capital Humano, Teoria do. In: CATTANI, Antonio David; HOL-ZMANN, Lorena. Dicionário de trabalho e tecnologia. Porto Alegre: UFRGS, 2006.

CORROCHANO, M. C. Jovens trabalhadores: expectativas de acesso ao ensino superior. Avaliação (Campinas): Sorocaba, v. 18, n.1, Mar. 2013.

Perspectivas em Gestão \& Conhecimento, João Pessoa, v. 9, n. 3, p. 81-101, set./dez. 2019. 
COSTA, F. de S. O PROUNI e seus egressos: uma articulação entre educação, trabalho e juventude. Interfaces da Educacao, v. 5, n. 14, p. 144-156, 2015.

DALAROSA, A. A.; SOUZA, J. P. de. Orientações internacionais nas políticas de educação e trabalho para a juventude no contexto brasileiro. Conjectura: filosofia e educação, v. 19, n. 2 , p. 84-107, 2014.

DUBAR, C. La construction sociale de l'insertion professionnelle. Éducation et Sociétés. n. 7, 2001/1, p. 23-36.

EUFRASIO, M. A. P. A inserção da juventude no mercado de trabalho na América latina: experiências sociais de afirmação dos direitos humanos. Revista Eletrônica Direito e Sociedade-REDES, v. 2, n. 1, p. 61-72, 2015.

FILHO, L. A. da S.; SILVA, F. J. F. da; QUEIROZ, S. N. de. Jovens no mercado de trabalho formal brasileiro: uma análise quantitativa. Revista Facultad de Ciencias Económicas: Investigación y Reflexión, v. 23, n. 2, 2015.

GIRARDO, C.; SILES, O. M. La Cooperación Internacional para la formación e inserción sociolaboral de jóvenes mexicanos. Revista latinoamericana de Ciencias Sociales, Niñez y Juventud, v. 10, n. 1, 2012.

GOBBO, R. M.; AMBROSETTI, N. B. Atração e inserção profissional de bolsistas egressos do Pibid Taubaté. Revista Univap, v. 22, n. 40, p. 418, 2017.

GONÇALVES, C. M. et al. Os jovens, a formação profissional e o emprego: resultados de uma investigação internacional. Sociologia: Revista da Faculdade de Letras da Universidade do Porto, v. 8, 2017.

GUILLAND, R.; MONTEIRO, J. k. Jovens e desemprego: estado da arte. Revista Psicologia Organizações e Trabalho, v.10, n.2, p. 145-158, 2010.

GUIMARÃES, N. A. Trajetórias juvenis. Um novo nicho em meio à expansão das oportunidades de trabalho. In: MACAMBIRA, J.; ANDRADE, F. R. B. (Orgs.). Trabalho e Formação Profissional: Juventudes em Transição. Fortaleza: IDT, UECE, BNB, 2013, p. 37-55.

HAYASHI, M. C. P. I. et al. Competências informacionais para utilização da análise bibliométrica em educação e educação especial. Educação Temática Digital, v. 7, n. 1, p. 11, 2005.

INSTITUTO BRASILEIRO DE GEOGRAFIA E ESTATíSTICA. Pesquisa Nacional por Amostra de Domicílios Contínua: Terceiro Trimestre de 2017. In: INSTITUTO BRASILEIRO DE GEOGRAFIA E ESTATÍSTICA. Indicadores IBGE. Brasília. 2017. Disponível em < https://www.ibge.gov.br/estatisticas-novoportal/sociais/trabalho/17270- pnadcontinua.html> Acesso em: dezembro de 2017.

LARANJEIRA, D. H. P.; TEIXEIRA, A. M. F.; BOURDON, S. Juventude, trabalho, educação: os jovens são o futuro do Brasil?. Caderno CRH, v. 20, n. 49, 2007.

LAUER-LEITE, I. D.; MOREIRA, Al. da S. Expectativas quanto ao primeiro emprego: a visão de universitários dos cursos de administração, sistemas de informação e economia. Administração: Ensino e Pesquisa, v. 11, n. 1, p. 11-29, 2010.

LEMOS, A. H. da C.; NEVES, D. R.; RODRIGUES, P. dos R. F. Inserção de alunos bolsistas no mercado de trabalho: qual o valor do diploma brasileiro? Revista Pensamento Contemporâneo em Administração, v.7, n.4, p.24-41, 2013 
LUCAS, J. C. S.; BALIBREA, L. F. A crise de oportunidades para os jovens com baixo nível de escolaridade em Espanha (2005-2014). Revista Portuguesa de Educação, v. 29, n. 2, p. 287327, 2016.

MACIAS-CHAPULA, C. A. O papel da informetria e da cienciometria e sua perspectiva nacional e internacional. Ciência da informação, v. 27, n. 2, 1998.

MAGALDI, J. C. M.; LIMA, R. de C. P. Surdez e inserção profissional: representações sociais de universitários surdos. Revista Espaço. N. 36, p. 61, jul-dez, 2011

MAIA, A. A. R. M.; MANCEBO, D. Juventude, trabalho e projetos de vida: ninguém pode ficar parado. Psicologia: ciência e profissão, v. 30, n. 2, p. 376-389, 2010.

MARCOLINO; A.; HORIE, L.; PELATIERI, P. Negociação coletiva e a regulamentação do trabalho juvenil no Brasil. 2013. In: MACAMBIRA, J.; ANDRADE, F. R. B. (Orgs.). Trabalho e Formação Profissional: Juventudes em Transição. Fortaleza: IDT, UECE, BNB, 2013, p. 193-203.

MARQUES, Amanda Cristina Teagno Lopes. Inserção profissional dos egressos de um curso de Licenciatura em Física. Revista Electrónica de Enseñanza de las Ciencias, v. 16, n. 1, 2017.

MARTINS, H. H. T. de S. O processo de reestruturação produtiva e o jovem trabalhador: conhecimento e participação. Tempo social, v. 13, n. 2, p. 61-87, 2001.

MELO, S. L. de; BORGES, L. de O. A transição da universidade ao mercado de trabalho na ótica do jovem. Psicologia: ciência e profissão, v. 27, n. 3, p. 376-395, 2007.

MENEZES, W. F.; UCHOA, C. F. A. A inserção do jovem no mercado de trabalho brasileiro. In: MACAMBIRA, J.; ANDRADE, F. R. B. (Orgs.). Trabalho e Formação Profissional: Juventudes em Transição. Fortaleza: IDT, UECE, BNB, 2013, p. 105-132.

MORETTO, A.; REMY, M. A. P. de. Dinâmica recente da inserção do jovem no mercado de trabalho e a questão da escolaridade. In: MACAMBIRA, J.; ANDRADE, F. R. B. (Orgs.). Trabalho e Formação Profissional: Juventudes em Transição. Fortaleza: IDT, UECE, BNB, 2013, p. 133153.

MUNIZ, L. B.; MEDEIROS, R. Juventude e trabalho na sociedade contemporânea: transformações, expectativas e possibilidades em meio a lógica da empregabilidade para os jovens do Plug Minas. Politica \& Trabalho, n. 42, 2015.

NAKANO, M.; ALMEIDA, E. de. Reflexões acerca da busca de uma nova qualidade da educação: relações entre juventude, educação e trabalho. Educação \& Sociedade, v. 28, n. 100, 2007.

NEVES, D. P. Juventude, trabalho e instituições filantrópicas. Saúde e Sociedade, v. 15, p. 99 114, 2006.

NUNES, H. P. Supply and demand of jobs for young people in the metropolitan area of Goiânia (2010-2013). Revista Brasileira de Desenvolvimento Regional, v. 2, n. 2, p. 133-152, 2015.

NUNES, S. R. dos R. Fazer o que gosta, gostar do que faz: jovens estudantes e o (s) mundo (s) do trabalho. 2018.

OLIVEIRA, L. B. de; WETZEL, U. Rumo ao mercado de trabalho: percepções e estratégias de jovens estudantes de Administração. Anais do II Encontro de Gestão de Pessoas e Relações de Trabalho. Curitiba, 2009.

OLIVEIRA, P. W. S. de. Construção de identidades profissionais: da formação profissional à vivência da inserção no mercado de trabalho. Revista Labor, v. 1, n. 6, 2011.

Perspectivas em Gestão \& Conhecimento, João Pessoa, v. 9, n. 3, p. 81-101, set./dez. 2019. 
OLIVEIRA, T. D.; GOLGHER, A. B.; LOUREIRO, P. M. Trajetórias de local de moradia, estudo e trabalho dos jovens brasileiros entre 2003 e 2011: uma análise de entropia. Revista Brasileira de Estudos de População, v. 33, n. 1, p. 31-52, 2016.

OSTROVSKI, C. S.; SOUSA, C. M. de; RAITZ, T. R. Expectativas com a carreira docente: escolha e inserção profissional de estudantes de Pedagogia. Revista Brasileira de Estudos Pedagógicos, v. 98, n. 248, 2017.

PEREGRINO, M.. Juventude, trabalho e escola: elementos para análise de uma posição social fecunda. Cadernos CEDES, Campinas, v. 31, n. 84, 2011.

PEUGNY, C.. O destino vem do berço. Desigualdades e reprodução social, 2014.

RAITZ, T. R.; PETTERS, L. C. F. Novos desafios dos jovens na atualidade: trabalho, educação e família. Psicologia \& Sociedade, v. 20, n. 3, 2008.

RAZA, C.; LALLI, L. C. A educação e o jovem frente ao exigente mercado de trabalho brasileiro. Revista Científica Hermes, n. 8, 2013.

REIS, C. N. dos; PANOZZO, V. M.; DORNELLES, A. E. Juventude latino-americana e mercado de trabalho: programas de capacitação e inserção. Revista Katalysis, 2016.

RIBEIRO, M. A. Juventude e trabalho: construindo a carreira em situação de vulnerabilidade. Arquivos Brasileiros de Psicologia, v. 63, 2011.

ROCHA, N. M. F. D.; GÓIS, C. W. de L. Trajetórias de jovens no mundo do trabalho a partir da primeira inserção: o caso de Sísifo em Maracanaú-Ceará, Brasil. Psicologia \& Sociedade, v. 22, n. 3, p. 466-475, 2010.

ROCHA-DE-OLIVEIRA, S. Inserção Profissional: perspectivas teóricas e agenda de pesquisa. Revista Pensamento Contemporâneo em Administração, v. 6, n. 1, 2012.

ROCHA-DE-OLIVEIRA, S.; PICCININI, V. C. Contribuições das abordagens francesas para o estudo da inserção profissional. Revista Brasileira de Orientação Profissional, Jan./Jun., vol. 13, n. 1, 2012a, p. 63-73.

ROCHA-DE-OLIVEIRA, S.; PICCININI, V. C. Uma análise sobre a inserção profissional de estudantes de administração no Brasil. RAM. Revista de Administração Mackenzie, v. 13, n. 2, 2012.

ROCHA-DE-OLIVEIRA, S.; PICCININI, V. C. Uma Análise sobre a Inserção Profissional de Estudantes de Administração no Brasil. Revista de Administração Mackenzie, v. 13, n. 2. São Paulo, SP: mar/abr, 2012b, p. 44-75.

RODRIGUES, I. J.; MARTINS, H. H. T. de S. Perfil socioeconômico de jovens metalúrgicos. Tempo Social, v.17, n.2, p. 221-252, 2005.

SANTOS, A. L. dos; GIMENEZ, D. Inserção dos jovens no mercado de trabalho. Estudos Avançados, v. 29, n. 85, p. 153-168, 2015.

SANTOS, M. L. de M.; CUNHA, M. M. Juventude entre a escola e o mercado de trabalho: o suor de meu trabalho é o impedimento de minha formação escolar. Eventos Pedagógicos, v. 4, n. 1, p. 138-148, 2013.

SILVA, M. R. da; PELISSARI, L. B.; STEIMBACH, A. A. Juventude, escola e trabalho: permanência e abandono na educação profissional técnica de nível médio. Educação e Pesquisa, v. 39, n. 2 , p. 403-417, 2013.

Perspectivas em Gestão \& Conhecimento, João Pessoa, v. 9, n. 3, p. 81-101, set./dez. 2019. 
SIMÕES, P. H. de C.; ALVES, J. E. D; SILVA, P. L. do N. Transformações e tendências do mercado de trabalho no Brasil entre 2001 e 2015: paradoxo do baixo desemprego?. Revista Brasileira de Estudos de População, v. 33, n. 3, p. 541-566, 2016.

SOTO, F. G. Transformaciones del trabajo y juventud: temas de búsqueda. Ultima década, v.17, n.31, p. 179-223, 2009.

SOUSA, L. N. Emprego e Trajetórias Profissionais: o caso dos diplomados do Instituto Superior Politécnico de Viseu. Sociologia: Revista da Faculdade de Letras da Universidade do Porto, v. 23, 2012.

SOUTO, F. A. B. P. et al. Transformações no mercado de trabalho recente e os jovens. In: MACAMBIRA, Júnior; ANDRADE, F. R. B. (Orgs.). Trabalho e Formação Profissional: Juventudes em Transição. Fortaleza: IDT, UECE, BNB, 2013, p. 169-230.

TARTUCE, G. Tensões e intenções na transição escola-trabalho: um estudo das vivências e percepções de jovens sobre os processos de qualificação profissional e (re)inserção no mercado de trabalho na cidade de São Paulo. Tese de doutorado. Universidade de São Paulo: São Paulo, 2007.

TOMÁS, M. C.; OlIVEIRA, A. M. H. C. de; NETO, E. L. G. Rios. Adiamento do ingresso no mercado de trabalho sob o enfoque demográfico: uma análise das regiões metropolitanas brasileiras. Revista Brasileira de Estudos de População, v. 25, n. 1, p. 91-107, 2008.

VINCENS, J. L'insertion dans la vie active. Institut des Sciences du Travail, L'insertion professionnelle à l'issue des études post-censitaires, dossier, n. 2, 1981.

VOLKMER MARTINS, B. Expansão e diversificação do ensino superior no Brasil: a mobilidade social e a inserção profissional dos jovens estudantes e egressos de cursos superiores tecnológicos na região metropolitana de Porto Alegre-RS. 2016. 435f. 2016. Tese de Doutorado. Tese (Doutorado em Administração) - Programa de Pós-Graduação em Administração, Escola de Administração, Universidade Federal do Rio Grande do Sul, Porto Alegre.

VOLKMER MARTINS, B.; OLIVEIRA, L. B. de; ROCHA-DE-OLIVEIRA, Sidinei. Rebaixamento de diplomas de jovens estudantes e egressos do ensino superior: proposta de escala de mensuração. XLI Encontro da ANPAD. São Paulo, São Paulo, 2017.

VOLKMER MARTINS, B.; ROCHA-DE-OLIVEIRA, S. A relação entre formação profissional e empregabilidade: em questão os jovens provenientes de cursos superiores de tecnologia. $\mathbf{X} \mathbf{L}$ Encontro da ANPAD. Costa do Sauipe, Bahia, 2016.

WICKERT, L. F. Desemprego e juventude: jovens em busca do primeiro emprego. Psicologia Ciência e Profissão, v. 26, n. 2, 2006.

Artigo recebido em 26/10/2018 e aceito para publicação em 07/09/2019

Perspectivas em Gestão \& Conhecimento, João Pessoa, v. 9, n. 3, p. 81-101, set./dez. 2019. 